Esta revista forma parte del acervo de la Biblioteca Jurídica Virtual del Instituto de Investigaciones Jurídicas de la UNAM

\title{
ESTUDIO SOBRE REDES FAMILIARES Y CLIENTELARES EN EL CONSEJO DE LA JUDICATURA FEDERAL
}

\author{
Felipe BORREGO ESTRADA*
}

\begin{abstract}
SUMARIO: I. Introducción. II. El artículo 134 de la Constitución y los deberes administrativo-judiciarios: imparcialidad, objetividad, transparencia. III. La designación de los funcionarios del Poder Judicial. IV. El servicio civil de carrera. V. El acceso a la carrera judicial. VI. Metodología empleada.
\end{abstract}

\section{INTRODUCCIÓN}

México es el país número 123, entre 176, de acuerdo con el Índice de Percepción de la Corrupción de Transparencia Internacional de 2016. En un año cayó 28 posiciones. Es el último lugar entre los 34 países de la OCDE. El World Justice Program, que hace hincapié en el funcionamiento de los aparatos judiciarios, ubica a nuestro país dentro de los 20 países con los servidores públicos más corruptos, según el índice de Estado de derecho (2014).

Los jueces, tanto locales como federales, son desvalorados en México, con niveles similares a los de los partidos políticos, las policías y las agencias del Ministerio Público. La inadecuada designación del personal administrativo y jurisdiccional, la generación de redes clientelares, el nepotismo, los enroques injustificados y la falta de respeto al escalafón judiciario contribuyen, sin duda, a esa percepción.

Nuestro imaginario percibe a la corrupción como algo necesariamente asociado al soborno o al peculado. La verdad es que posee otras manifestaciones. Todas las contrataciones que realice el gobierno, incluidas las de los puestos laborales, deben atender a criterios de ob-

\footnotetext{
* Consejero de la Judicatura Federal.
} 
Esta revista forma parte del acervo de la Biblioteca Jurídica Virtual del Instituto de Investigaciones Jurídicas de la UNAM

\section{FELIPE BORREGO ESTRADA}

jetividad, transparencia y eficiencia. Circuitos judiciales en los que porcentajes sorprendentemente altos de funcionarios poseen parientes (algunos llegan al 66.03\%) hablan no sólo de tendencias nepóticas, sino de potenciales redes clientelares que son, en sí mismas, conductas reprochables desde el punto de vista de la correcta administración de los haberes públicos. Para el ministro jubilado de la Suprema Corte de Justicia José Trinidad Lanz Cárdenas "una de las formas más socorridas de corrupción en el servicio público y principalmente en la administración pública lo viene a constituir el nepotismo". ${ }^{1}$

Quisimos iniciar con una gráfica muy representativa pues es imprescindible comenzar teniendo en consideración la magnitud del problema al que nos enfrentamos.

\section{DATOS ESTADÍSTICOS DE SERVIDORES PÚBLICOS CON FAMILIARES²}

\begin{tabular}{|l|l|c|c|c|}
\hline Circuito & \multicolumn{1}{|c|}{$\begin{array}{c}\text { Titulares con } \\
\text { familiares }\end{array}$} & $\begin{array}{c}\text { Servidores públicos } \\
\text { con familiares } \\
\text { (sin titulares) } \\
-\end{array}$ & $\begin{array}{c}\text { - } \\
\text { Total de plazas } \\
\text { para titulares } \\
\text { en el circuito } \\
\text { Total de servidores } \\
\text { públicos con } \\
\text { familiares } \\
\text { (incluyendiliares } \\
\text { (sin titulares) }\end{array}$ & $\begin{array}{c}\text { Total de servidores) } \\
\text { públicos }\end{array}$ \\
\hline Segundo & $\begin{array}{l}\text { Estado } \\
\text { de México } 4\end{array}$ & $27-4757.45 \%$ & $135-121811.08 \%$ & $162-126512.81 \%$ \\
\hline Tercero & Jalisco & $57-7576 \%$ & $478-295316.19 \%$ & $535-302817.67 \%$ \\
\hline Cuarto & Nuevo León & $35-5662.5 \%$ & $563-149037.79 \%$ & $598-154638.68 \%$ \\
\hline Quinto & Sonora & $13-3834.21 \%$ & $562-117847.71 \%$ & $575-121647.29 \%$ \\
\hline Sexto & Puebla & $34-6651.52 \%$ & $450-144531.14 \%$ & $484-151132.03 \%$ \\
\hline Séptimo & Veracruz & $26-5349.06 \%$ & $128-12889.94 \%$ & $154-134111.48 \%$ \\
\hline
\end{tabular}

1 Lanz Cárdenas, José Trinidad, "Reflexiones sobre Derecho Constitucional, Amparo, Ética Jurídica y Nepotismo", Ensayos y Conferencias de los forjadores de la Suprema Corte de Justicia de la Nación, SCJN, México, 2013, p. 117.

2 Los datos pueden sufrir constante variación, en razón de la movilidad laboral que se experimenta en el Consejo de la Judicatura Federal. Pueden asimismo hallarse incompletos en razón de las limitaciones en el acceso a la información. En cualquier caso, manteniéndose las variables conforme a un patrón ordinario, las variaciones estadísticas resultan de menor envergadura.

3 Incluye magistrados de circuito y jueces de distrito.

4 Los datos obtenidos en el Segundo Circuito corresponden únicamente a los órganos jurisdiccionales ubicados en Toluca, Estado de México, debido a que en los ubicados en Nezahualcóyotl y Naucalpan no se pudo obtener información. 
Esta revista forma parte del acervo de la Biblioteca Jurídica Virtual del Instituto de Investigaciones Jurídicas de la UNAM http://www.juridicas.unam.mx/

ESTUDIO SOBRE REDES FAMILIARES Y CLIENTELARES...

\begin{tabular}{|c|c|c|c|c|}
\hline Circuito & Estado & $\begin{array}{c}\text { Titulares con } \\
\text { familiares }^{3} \\
- \\
\text { Total de plazas } \\
\text { para titulares } \\
\text { en el circuito }\end{array}$ & $\begin{array}{l}\text { Servidores públicos } \\
\text { con familiares } \\
\text { (sin titulares) } \\
- \\
\text { Total de servidores } \\
\text { públicos con } \\
\text { familiares } \\
\text { (sin titulares) }\end{array}$ & $\begin{array}{c}\text { Servidores públicos } \\
\text { con familiares } \\
\text { (incluyendo titulares) } \\
- \\
\text { Total de servidores } \\
\text { públicos }\end{array}$ \\
\hline Octavo & Coahuila & $20-5040 \%$ & 218-1041 20.94\% & 238-1091 21.81\% \\
\hline Noveno & $\begin{array}{l}\text { San Luis } \\
\text { Potosí }\end{array}$ & $16-2369.57 \%$ & $210-66631.53 \%$ & $226-68932.80 \%$ \\
\hline Décimo & Tabasco & $9-3724.32 \%$ & $82-8489.67 \%$ & $91-88510.28 \%$ \\
\hline $\begin{array}{l}\text { Décimo } \\
\text { Primero }\end{array}$ & Michoacán & $14-3540 \%$ & $159-86018.49 \%$ & $173-89519.33 \%$ \\
\hline $\begin{array}{l}\text { Décimo } \\
\text { Segundo }\end{array}$ & Sinaloa & $15-5129.41 \%$ & $370-105535.07 \%$ & $385-110634.81 \%$ \\
\hline $\begin{array}{l}\text { Décimo } \\
\text { Tercero }\end{array}$ & Oaxaca & $4-2516 \%$ & $45-6427.01 \%$ & $49-6677.35 \%$ \\
\hline $\begin{array}{l}\text { Décimo } \\
\text { Cuarto }\end{array}$ & Yucatán & $8-2138.1 \%$ & $175-48935.79 \%$ & $183-51035.88 \%$ \\
\hline $\begin{array}{l}\text { Décimo } \\
\text { Quinto }\end{array}$ & Baja California & $32-5855.17 \%$ & $515-170530.21 \%$ & $547-176331.03 \%$ \\
\hline $\begin{array}{l}\text { Décimo } \\
\text { Sexto }\end{array}$ & Guanajuato & $38-4682.61 \%$ & $438-121436.08 \%$ & $476-126037.78 \%$ \\
\hline $\begin{array}{l}\text { Décimo } \\
\text { Séptimo }\end{array}$ & Chihuahua & $12-3737.84 \%$ & $427-79553.71 \%$ & $441-83253.00 \%$ \\
\hline $\begin{array}{l}\text { Décimo } \\
\text { Octavo }\end{array}$ & Morelos & $16-3250 \%$ & $150-85217.61 \%$ & $166-88418.78 \%$ \\
\hline $\begin{array}{l}\text { Décimo } \\
\text { Noveno }\end{array}$ & Tamaulipas & $18-4440.91 \%$ & $181-115515.67 \%$ & $199-119916.60 \%$ \\
\hline Vigésimo & Chiapas & $13-2846.43 \%$ & $205-86223.78 \%$ & $218-89024.49 \%$ \\
\hline $\begin{array}{l}\text { Vigésimo } \\
\text { Primero }\end{array}$ & Guerrero & $12-3930.77 \%$ & $322-117327.45 \%$ & $334-121227.56 \%$ \\
\hline $\begin{array}{l}\text { Vigésimo } \\
\text { Segundo }\end{array}$ & Querétaro & $14-2556 \%$ & $176-56431.21 \%$ & $190-58932.26 \%$ \\
\hline $\begin{array}{l}\text { Vigesimo } \\
\text { Tercero }\end{array}$ & Zacatecas & $9-2045 \%$ & $118-34534.20 \%$ & $127-36534.79 \%$ \\
\hline $\begin{array}{l}\text { Vigésimo } \\
\text { Cuarto }\end{array}$ & Nayarit & 5-18 27.78\% & $230-59838.46 \%$ & $235-61638.15 \%$ \\
\hline $\begin{array}{l}\text { Vigésimo } \\
\text { Quinto }\end{array}$ & Durango & $6-1346.15 \%$ & $59-34517.10 \%$ & $65-35818.16 \%$ \\
\hline
\end{tabular}


Esta revista forma parte del acervo de la Biblioteca Jurídica Virtual del Instituto de Investigaciones Jurídicas de la UNAM

FELIPE BORREGO ESTRADA

\begin{tabular}{|c|c|c|c|c|}
\hline Circuito & Estado & $\begin{array}{c}\text { Titulares con } \\
\text { familiares }^{3} \\
- \\
\text { Total de plazas } \\
\text { para titulares } \\
\text { en el circuito }\end{array}$ & $\begin{array}{l}\text { Servidores públicos } \\
\text { con familiares } \\
\text { (sin titulares) } \\
- \\
\text { Total de servidores } \\
\text { públicos con } \\
\text { familiares } \\
\text { (sin titulares) }\end{array}$ & $\begin{array}{c}\text { Servidores públicos } \\
\text { con familiares } \\
\text { (incluyendo titulares) } \\
- \\
\begin{array}{c}\text { Total de servidores } \\
\text { públicos }\end{array}\end{array}$ \\
\hline $\begin{array}{l}\text { Vigésimo } \\
\text { Sexto }\end{array}$ & Baja Sur & $7-1353.85 \%$ & $83-29428.23 \%$ & $90-30729.32 \%$ \\
\hline $\begin{array}{l}\text { Vigésimo } \\
\text { Séptimo }\end{array}$ & Quintana Roo & $9-2142.86 \%$ & $136-51126.61 \%$ & $145-53227.26 \%$ \\
\hline $\begin{array}{l}\text { Vigésimo } \\
\text { Octavo }\end{array}$ & Tlaxcala & $7-1070 \%$ & $128-27945.88 \%$ & $135-28946.71 \%$ \\
\hline $\begin{array}{l}\text { Vigésimo } \\
\text { Noveno }\end{array}$ & Hidalgo & $6-1540 \%$ & $78-35821.79 \%$ & $84-37322.52 \%$ \\
\hline Trigésimo & Aguascalientes & $13-1681.25 \%$ & $130-41231.55 \%$ & $143-42833.41 \%$ \\
\hline $\begin{array}{l}\text { Trigésimo } \\
\text { Primero }\end{array}$ & Campeche & $4-944.44 \%$ & $59-20029.5 \%$ & $63-20930.14 \%$ \\
\hline $\begin{array}{l}\text { Trigésimo } \\
\text { Segundo }\end{array}$ & Colima & $2-1020 \%$ & $136-19968.34 \%$ & $138-20966.03 \%$ \\
\hline
\end{tabular}

La designación no objetiva ni transparente de funcionarios, en cualquiera de los tres departamentos en los que tradicionalmente se ha dividido el ejercicio del poder público, genera potenciales conflictos de interés y bien puede ser catalogada como una conducta que, en razón de su potencialidad corruptora, exige medidas correctivas en los niveles administrativos y regulatorios.

Con este estudio se pretende, al alimón, realizar un diagnóstico del problema que en cuanto a la potencialización de conflictos de interés se da al interior del Consejo de Judicatura Federal (CJF) y proponer perspectivas de solución, bien sea al aprovechar el actual proceso de confección de una nueva Ley del Servicio Profesional de Carrera que podría incluir a los tres poderes de la Unión, bien al delinear una regulación específica para el Poder Judicial tanto en el ámbito administrativo como en el jurisdiccional.

México cuenta hoy con 12 distintos servicios de carrera, nada homogéneos y mal alineados. El Poder Judicial de la Federación (PJF) puede marcar la pauta y ser un ejemplo a seguir para los otros departamentos del poder público y para los órganos constitucionalmente autónomos. El Nepotismo y las redes clientelares, empero, pueden significarse como obstáculos en forma alguna despreciables. 
Esta revista forma parte del acervo de la Biblioteca Jurídica Virtual del Instituto de Investigaciones Jurídicas de la UNAM

ESTUDIO SOBRE REDES FAMILIARES Y CLIENTELARES...

El reto está, primero, en aceptar la magnitud del problema y, después, en dar ejemplo de respuesta rápida, efectiva y dignificatoria.

Los nombramientos de funcionarios en los órganos jurisdiccionales son facultad exclusiva de jueces y magistrados, según establece el artículo 97 constitucional. El precepto se explica: quiso dotarse de un grado de autonomía de gestión a los titulares de los mismos. Es evidente, sin embargo, que la disposición generó externalidades que deben corregirse. Como se mostrará en este estudio, expone a los juzgadores a caer en conflictos de interés y provoca que surjan dudas fundadas en cuanto a la imparcialidad de los juzgados y tribunales.

En el caso del CJF, es apreciable, al analizar los números totales, que los casos fuertes de nepotismo se presentan, además de entre jueces y magistrados, en los niveles de secretario e inferiores. Existe en ese caso una fuerte red clientelar que, encima, carece de deslinde de responsabilidades: ni los secretarios ni los oficiales nombran a funcionario alguno. Se advierte que, sin embargo, participan activamente e influyen en los nombramientos, bien sea en sus propios órganos jurisdiccionales, circuitos, o bien en diversas jurisdicciones.

Resulta en consecuencia deseable establecer trabas para los nombramientos sospechosos de nepotismo, endogamia o clientelismo, así como figuras que consideramos eficaces para la estructuración de un imparcial y objetivo servicio de carrera, como es la institución del examen de habilitación previa a cualquier designación.

\title{
II. EL ARTÍ́CULO 134 DE LA CONSTITUCIÓN Y LOS DEBERES ADMINISTRATIVO-JUDICIARIOS: IMPARCIALIDAD, OBJETIVIDAD, TRANSPARENCIA
}

\begin{abstract}
¿Por qué obligan los principios del artículo 134 constitucional a las contrataciones, incluso a las administrativas, en el seno del Poder Judicial de la Federación?
\end{abstract}

Porque el artículo 134 de la Constitución general de la República no distingue: todas las contrataciones del gobierno, aún las laborales y en cualquiera de los poderes, deben realizarse con objetividad e imparcialidad, con sentido de eficacia y eficiencia. Ello implica remover todos los obstáculos que impidan la imparcialidad, incluyendo aquellas hipótesis que eventualmente podrían poner en duda la objetividad del tomador de decisiones. 
Esta revista forma parte del acervo de la Biblioteca Jurídica Virtual del Instituto de Investigaciones Jurídicas de la UNAM

\section{FELIPE BORREGO ESTRADA}

La designación del personal en el Poder Judicial de la Federación debe atender a los criterios del artículo 134 tanto para la eficacia como para la objetividad. No existe razón alguna de orden constitucional que pueda sugerir otra cosa. De hecho, siendo el Poder Judicial el guardián por excelencia de los principios constitucionales, es la sede paradigmática para que se cumplan los relativos a las contrataciones del personal. Más aún, si se piensa en el reforzado nivel de objetividad que debe poseer el juzgador.

En general, la doctrina es pacífica en aceptar que las contrataciones y adscripciones de personal administrativo y jurisdiccional que se realizan tomando en cuenta criterios subjetivos (bien sea afectivos, familiares, de interés político o económico):

a) Minan la legitimidad de las decisiones administrativas y jurisdiccionales.

b) Fomentan el tráfico de influencias.

c) Incentivan la opacidad y repercuten negativamente en la rendición de cuentas.

d) Propician conductas corruptas.

e) Generan el empoderamiento de determinados sectores al interior de los órganos jurisdiccionales (en nuestro objeto de estudio, esto se aprecia particularmente en los casos de secretarios y oficiales judiciales).

f) Crean redes de intereses clientelares entre servidores públicos de diversos juzgados y circuitos.

g) Generan discrecionalidad en la toma de decisiones, lo que va aunado a la expedición de criterios regulatorios contradictorios.

h) Afectan negativamente la percepción pública del Poder Judicial, lo cual mina los cimientos mismos del Estado constitucional y democrático de derecho, al tiempo en que entorpece el combate a la corrupción (que se complica aún fuera del Poder Judicial) y la tutela efectiva de los derechos humanos, en especial por lo que respecta al acceso a la justicia.

Las siguientes láminas muestran cómo, según algunos baremos, los jueces inspiran menos confianza que la Policía Federal o la Procuraduría General de la República y son percibidos como más corruptos que el Ministerio Público, las Procuradurías y algunos cuerpos policiales. Motivo suficiente para la alarma, en el que, tal vez, el diseño institucional y orgánico, en particular por lo que respecta a los mecanismos de designación, permanencia y traslación de funcionarios, tenga algo que decirnos. 
Esta revista forma parte del acervo de la Biblioteca Jurídica Virtual del Instituto de Investigaciones Jurídicas de la UNAM http://www.juridicas.unam.mx/ https://biblio.juridicas.unam.mx/bjv

https://revistas.juridicas.unam.mx/

DOI: http://dx.doi.org/10.22201/iij.24487929e.2017.26.12316

ESTUDIO SOBRE REDES FAMILIARES Y CLIENTELARES...

Población de 18 años y más, por tipo de autoridad que identifica según el nivel de confianza que ésta le inspira

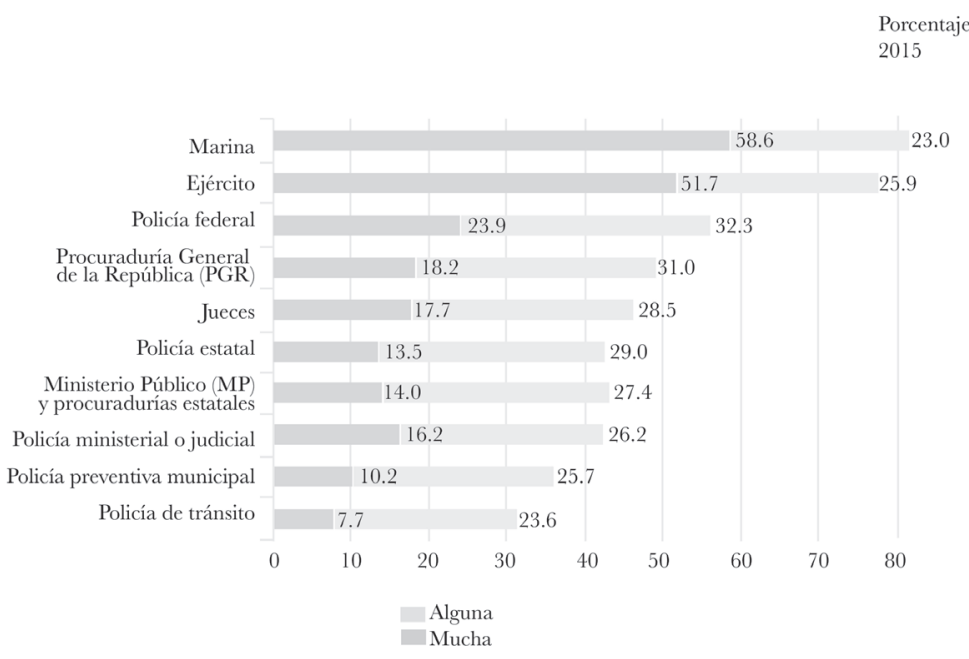

Fuente: INEGI, Encuesta Nacional de Victimización y Percepción sobre Seguridad Pública 2015.

Población de 18 años y más, por tipo de autoridad que identifica que es corrupta

Porcentaje

2014

Policía de tránsito

Policía preventiva municipal

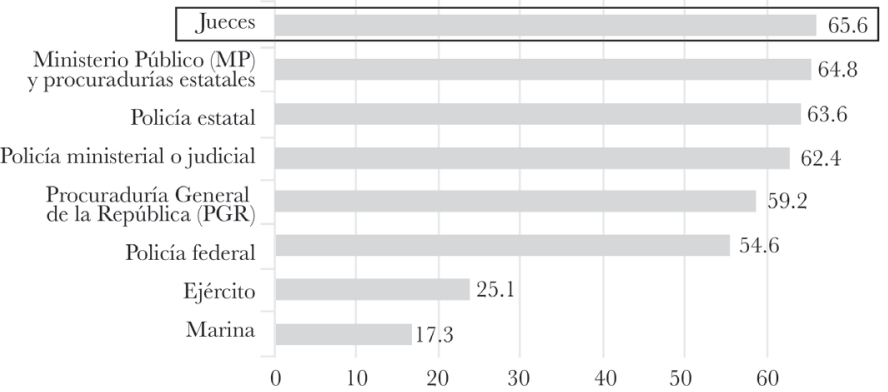

Fuente: INEGI, Encuesta Nacional de Victimización y Percepción sobre Seguridad Pública 2015.

BJV, Instituto de Investigaciones Jurídicas-UNAM, 2018 https://revistas.juridicas.unam.mx/index.php/reforma-judicial/issue/archive 
Esta revista forma parte del acervo de la Biblioteca Jurídica Virtual del Instituto de Investigaciones Jurídicas de la UNAM

\section{FELIPE BORREGO ESTRADA}

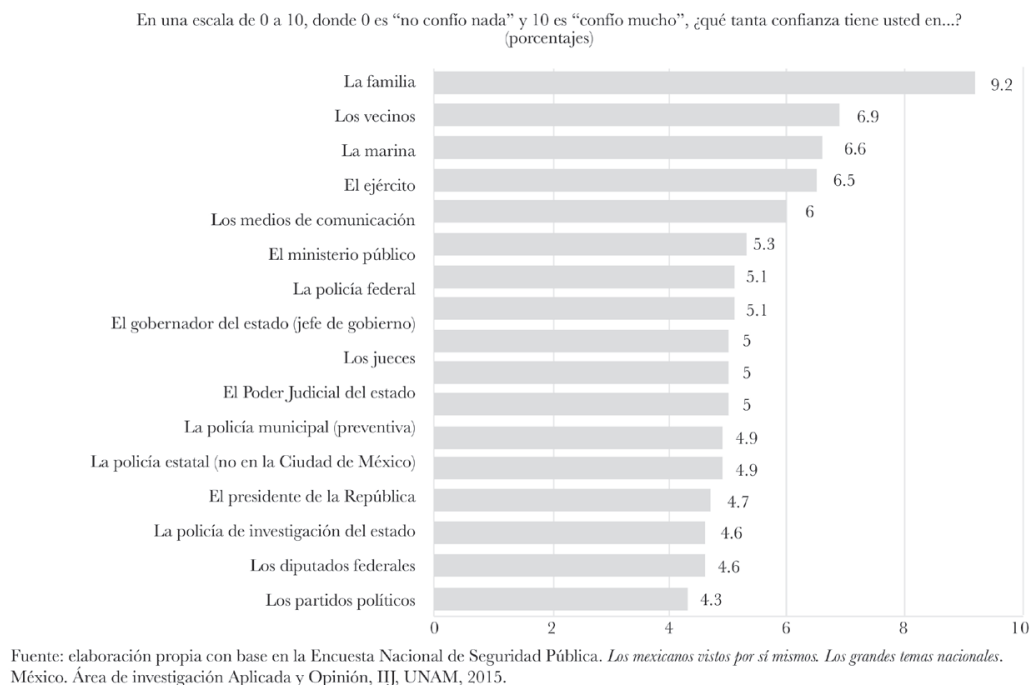

No basta, desde luego, con argumentar que la categoría jueces incluye a las jurisdicciones locales, lo que en efecto ocurre. En lo federal, es un hecho que los temas de nepotismo y redes clientelares generan críticas crecientes: la percepción y reconocimiento del juzgador federal ha bajado, y el tema del nepotismo es más perceptible y de mayores dimensiones en la jurisdicción federal.

La percepción negativa se incrementa, en nuestra hipótesis, por cuatro razones principales:

a) Falta de regulación adecuada, con parámetros objetivos para la contratación del personal y para el ingreso al cauce de la carrera judicial.

b) Ausencia de criterios firmes para evitar las adscripciones con criterios de parentesco o clientelares, lo que en los últimos tiempos se ha traducido en la denuncia pública de los llamados "enroques" entre órganos jurisdiccionales del mismo circuito o de circuitos distintos, o bien en nombramientos nepóticos y/o endogámicos en las áreas centrales del CJF.

c) Permisividad de las políticas institucionales.

d) Mal entendimiento del principio de inamovilidad, que ha provocado que los juzgadores se eternicen en sus adscripciones, dando pie a la generación de redes clientelares longevas. 
Esta revista forma parte del acervo de la Biblioteca Jurídica Virtual del Instituto de Investigaciones Jurídicas de la UNAM

ESTUDIO SOBRE REDES FAMILIARES Y CLIENTELARES...

Según el principio no. 10 de Naciones Unidas relativo a la independencia del Poder Judicial (en los sucesivo Principios), ningún motivo más allá de lo judicial debe permear en la selección de juzgadores. Ahora bien, un adecuado entramado administrativo permite al juez desempeñar sus tareas con mayor grado de acierto, por lo que es perfectamente posible extender el criterio de no discriminación y preocupación exclusiva por el mejor desempeño, el mérito y la capacidad de lo jurisdiccional, al nombramiento del personal de apoyo administrativo.

La Comisión Internacional de Juristas en su Guía sobre los Principios Internacionales sobre la Independencia y responsabilidad de Jueces, Abogados y Fiscales afirma que los tribunales deben gozar de todo tipo de salvaguardias contra presiones externar. El juez "debe ser visto como independiente". ${ }^{5} \mathrm{Y}$ es que, como establece el numeral 2 de los Principios "los jueces resolverán los asuntos que conozcan con imparcialidad, basándose en los hechos y en consonancia con el derecho, sin restricción alguna y sin influencias, alicientes, presiones, amenazas o intromisiones indebidas; sean directas o indirectas, de cualesquiera sectores o por cualquier motivo". Dentro de estos sectores o motivos bien podemos ubicar los chantajes provenientes de las redes de influencia administrativa, o las presiones del entorno familiar o sentimental.

La Guía es concluyente al respecto: "todos los Estados tienen el deber de establecer las salvaguardias necesarias para que los jueces puedan resolver cada causa de manera independiente". ${ }^{6}$ Sólo un criterio excesivamente laxo puede considerar que dentro de estas salvaguardias no se hallan las relativas a generar un entorno administrativo libre de influencias, chantajes y presiones.

Por supuesto, los jueces no deben tener "intereses en juego en un caso particular". 7 Por la naturaleza de su función, el tema del potencial conflicto de intereses adquiere en lo jurisdiccional matices muy peculiares. Un entramado administrativo-judiciario que lo fomente es del todo deplorable. El principio no. 8 de Naciones Unidas exige que los jueces se conduzcan "en todo momento de manera que se preserve la dignidad de sus funciones y la imparcialidad e independencia de la judicatura". Por lo que respecta al Estatuto del Juez Iberoamericano "la imparcialidad del juez ha de ser real, efectiva y evidente para la ciudadanía". Con

5 Comisión Internacional de Juristas, Guía sobre los Principios Internacionales sobre la Independencia y responsabilidad de Jueces, Abogados y Fiscales (en adelante se citará como Guía ), p. 25. En esto sigue varios criterios del Tribunal Europeo de Derechos Humanos.

6 Guía, p. 27.

7 Ibidem, p. 29. 
Esta revista forma parte del acervo de la Biblioteca Jurídica Virtual del Instituto de Investigaciones Jurídicas de la UNAM

\section{FELIPE BORREGO ESTRADA}

números y porcentajes de acreditados nepotismo y clientelismo como los que hemos señalado, es difícil que se tenga por evidente a nivel social la imparcialidad del PJF.

Los Principios de Bangalore sobre la Conducta Judicial son, si cabe, más explícitos. El Principio 2.5 dispone que "un juez se descalificará de participar en cualquier proceso en el que no pueda decidir el asunto en cuestión de forma imparcial, o, en el que pueda aparecer un observador razonable con el que el juez es incapaz de decidir el asunto imparcialmente". ${ }^{8}$ Pareciera que cualquier "observador razonable" concluiría que un entorno propicio a las redes clientelares no es el más adecuado para la toma de decisiones imparciales. En el mismo sentido, el artículo 9 del ya citado Estatuto del Juez Iberoamericano establece que "los jueces tienen la obligación se separarse de la tramitación y conocimiento de asuntos en los que tengan alguna relación previa con el objeto del proceso, partes o interesados en el mismo, en los términos previstos en la ley". Huelga decir que el nombramiento no objetivo de los funcionarios judiciales multiplica exponencialmente el riesgo de aparición de "interesados" en múltiples procesos.

En Indra c. Slovakia, el Tribunal Europeo de Derechos Humanos determinó que "cualquier juez con respecto a quien exista una razón legítima para dudar de su imparcialidad, debe retirarse del caso". Según los Principios y Directrices sobre el Derecho a un Juicio Justo y a las Asistencia Jurídica en África, la imparcialidad se ve socavada cuando un funcionario judicial actúa como miembro de un tribunal de apelaciones en asuntos que decidió en primera instancia. ${ }^{9}$ En breve veremos casos similares en los que la Suprema Corte mexicana se ha pronunciado en forma radicalmente opuesta.

La autonomía de un órgano jurisdiccional no sólo se predica respecto de los otros departamentos de ejercicio del poder público. La Guía reconoce que "ya que las otras ramas del poder público o instituciones del Estado ejercen una importante influencia en la asignación y administración de los recursos otorgados al Poder Judicial, existe una posibilidad real de influir en los resultados de casos particularmente sensibles, lo que podría implicar un ataque a la independencia del Poder Judicial. Para prevenir tal situación, varios estados han creado, dentro del Poder Judicial, organismos a cargo de administrar los recursos judiciales para fortalecer de este modo la autonomía del órgano judicial". ${ }^{10}$ Es claro que

\footnotetext{
8 Ibidem, p. 32. Las cursivas siempre son nuestras.

9 Ibidem, p. 33.

10 Ibidem, p. 35
} 
Esta revista forma parte del acervo de la Biblioteca Jurídica Virtual del Instituto de Investigaciones Jurídicas de la UNAM

ESTUDIO SOBRE REDES FAMILIARES Y CLIENTELARES...

algo así se pretendió realizar en México con la creación del Consejo de la Judicatura Federal aunque, como creemos haber demostrado, algunos efectos colaterales e indeseables se han venido multiplicando en materia de redes clientelares indebidas y riesgosas. De hecho, muchos funcionarios administrativos del CJF tienen parientes en órganos jurisdiccionales, y varios titulares de juzgados o tribunales han logrado que sus parientes sean contratados para plazas administrativas dentro del CJF.

Autonomía no es ni puede ser sinónimo de impunidad. Si bien es cierto que "el modo en que se gastan los recursos es un asunto interno del poder judicial, esa rama del poder es responsable ante las demás mediante el sistema de frenos y contrapesos". ${ }^{11}$ Inútil insistir en que las contrataciones laborales que no se realizan en forma objetiva, no resisten auditorías y generan responsabilidad.

\section{LA DESIGNACIÓN DE LOS FUNCIONARIOS DEL PODER JUDICIAL}

\section{Los exámenes de oposición y habilitación: hacia una Escuela Nacional de la Judicatura y la Administración Judicial}

Si ha quedado demostrado que el PJF debe realizar sus contrataciones en forma no sólo autónoma, sino objetiva y eficiente, resulta inconcuso que los nombramientos en instancias judiciales, así como en las correspondientes áreas administrativas, deben responder a pruebas de habilidad y competencia que trasciendan los criterios meramente subjetivos.

Es necesaria la recomposición del Instituto de la Judicatura Federal para convertirlo en una cabal Escuela Nacional no sólo en lo que respecta a la función propiamente jurisdiccional, sino en lo que toca a la administración judicial, con fuerte hincapié en lo que los anglosajones han Ilamado "especialidad en Legal Managment".

Para conseguir transformación semejante y cumplir con los extremos del artículo134 de la Constitución general de la República, dos instrumentos parecen particularmente útiles: la prueba de habilitación para el ingreso al cauce del servicio de carrera, y los exámenes de oposición para ocupar las plazas vacantes.

\footnotetext{
11 Ibidem, p. 38.
} 
Esta revista forma parte del acervo de la Biblioteca Jurídica Virtual del Instituto de Investigaciones Jurídicas de la UNAM

\section{FELIPE BORREGO ESTRADA}

2. La prevención del conflicto de interés y el combate a los criterios subjetivos de designación, adscripción y permanencia

\section{A. Marco jurídico y ético}

Definición de conflicto de intereses.

Hemos podido comprobar que el Estado tiene la obligación de brindar al justiciable un entorno que permita que la función jurisdiccional se desarrolle en forma imparcial, esto es, sin confluencia de intereses que sean ajenos a un genuino y exclusivo espíritu de justicia.

Una de las situaciones que lesionan de manera particular los intereses públicos, así como la percepción de confianza en el servicio público, es el conflicto de intereses.

Debemos partir del hecho que los conflictos de intereses y la corrupción no son lo mismo. La corrupción requiere generalmente de un acuerdo entre al menos dos socios y algún pago, soborno o ventaja de algún tipo. En cambio, un eventual conflicto de intereses surge cuando una persona puede tener la oportunidad de anteponer sus intereses privados a sus deberes profesionales.

Un conflicto de intereses que no se aborde debidamente en un procedimiento de contratación pública tiene un impacto en la regularidad de los procedimientos. Conduce a la infracción de los principios de transparencia, igualdad de trato o no discriminación que debe respetar todo contrato público:

Un conflicto de intereses es cuando un interés laboral, personal, profesional, familiar o de negocios de la persona servidora pública pueda afectar el desempeño imparcial, objetivo de sus funciones..$^{12}$

El conflicto de intereses se presenta cuando los intereses personales, familiares o de negocios del servidor público puedan afectar el desempeño imparcial de su empleo, cargo o comisión. ${ }^{13}$

Un "conflicto de intereses" es un conflicto entre el deber y los intereses privados de un empleado público cuando el empleado tiene a título particular intereses que podrían influir indebidamente en la forma correcta de ejercicio de sus funciones y responsabilidades oficiales. ${ }^{14}$

12 Página oficial de la Contraloría General de la Ciudad de México en: http://www. contraloria.cdmx.gob.mx/conflicto/.

13 Directrices en la ASF para Prevenir el Conflicto de Intereses, Cámara de Diputados, México, 2011, p. 6.

14 "Managing Conflict of Interest in the Public Service", OECD Guidelines and Country Experiences («La gestión de los conflictos de intereses en el servicio público», Líneas di- 
Esta revista forma parte del acervo de la Biblioteca Jurídica Virtual del Instituto de Investigaciones Jurídicas de la UNAM

ESTUDIO SOBRE REDES FAMILIARES Y CLIENTELARES...

El conflicto de intereses puede ser

\begin{tabular}{|l|l|}
\hline Potencial & $\begin{array}{l}\text { Cuando no hay conflicto de intereses en el momento, pero en un futuro } \\
\text { dadas ciertas circunstancias puede aparecer. }\end{array}$ \\
\hline Real & $\begin{array}{l}\text { Cuando un interés influye parcialmente en el desempeño de las actividades } \\
\text { de un servidor público. }\end{array}$ \\
\hline Aparente & $\begin{array}{l}\text { Cuando los intereses privados de un funcionario público son susceptibles de } \\
\text { influir indebidamente en el desempeño de sus funciones, pero este no es, de } \\
\text { hecho, el caso. De cualquier forma, puede tener impacto en la percepción } \\
\text { ciudadana acerca del ejercicio del poder público. }\end{array}$ \\
\hline
\end{tabular}

Para mostrar que la prevalencia de nombramientos nepóticos en la administración del PJF coloca a múltiples servidores en situación de riesgo por conflicto de interés, analizaremos exegéticamente las siguientes categorizaciones:

\section{B. Marco jurídico y ético relacionado con el conflicto de intereses}

Es obligación de los servidores públicos abstenerse de recibir propuestas, celebrar contratos o conceder beneficios a aquellas personas físicas o morales que incurran en alguno de los supuestos de impedimento que señala la ley o que no presenten su Manifestación de No Conflicto de Intereses.

A la fecha del presente estudio, continúa vigente la Ley Federal De Responsabilidades Administrativas De Los Servidores Públicos (LFRASP), que en su Título Segundo, Responsabilidades Administrativas, regula los "principios que rigen la función pública, sujetos de responsabilidad administrativa y obligaciones en el servicio público". Estos principios son de aplicación directa a los servidores del PJF. Lo propio ocurre con buena parte de LFRASP:

Artículo 7o. Será responsabilidad de los sujetos de la ley ajustarse, en el desempeño de sus empleos, cargos o comisiones, a las obligaciones previstas en ésta, a fin de salvaguardar los principios de legalidad, honradez, lealtad, imparcialidad y eficiencia que rigen en el servicio público.

Artículo 8o. Todo servidor público tendrá las siguientes obligaciones (sólo se mencionan las pertinentes a este análisis):

rectrices de la OCDE y experiencias nacionales), p.24-25, http://www.oecd.org/corruption/ ethics/48994419.pdf. 
Esta revista forma parte del acervo de la Biblioteca Jurídica Virtual del Instituto de Investigaciones Jurídicas de la UNAM

\section{FELIPE BORREGO ESTRADA}

I. Cumplir el servicio que le sea encomendado y abstenerse de cualquier acto u omisión que cause la suspensión o deficiencia de dicho servicio o implique abuso o ejercicio indebido de un empleo, cargo o comisión.

VI. Observar buena conducta en su empleo, cargo o comisión, tratando con respeto, diligencia, imparcialidad y rectitud a las personas con las que tenga relación con motivo de éste.

$\mathrm{XI}$. Excusarse de intervenir, por motivo de su encargo, en cualquier forma en la atención, tramitación o resolución de asuntos en los que tenga interés personal, familiar o de negocios, incluyendo aquéllos de los que pueda resultar algún beneficio para él, su cónyuge o parientes consanguíneos o por afinidad hasta el cuarto grado, o parientes civiles, o para terceros con los que tenga relaciones profesionales, laborales o de negocios, o para socios o sociedades de las que el servidor público o las personas antes referidas formen o hayan formado parte.

El servidor público deberá informar por escrito al jefe inmediato sobre la atención, trámite o resolución de los asuntos a que hace referencia el párrafo anterior y que sean de su conocimiento, y observar sus instrucciones por escrito sobre su atención, tramitación y resolución, cuando el servidor público no pueda abstenerse de intervenir en ellos.

XII. Habrá intereses en conflicto cuando los intereses personales, familiares o de negocios del servidor público puedan afectar el desempeño imparcial de su empleo, cargo o comisión.

XIV. Abstenerse de intervenir o participar indebidamente en la selección, nombramiento, designación, contratación, promoción, suspensión, remoción, cese, rescisión del contrato o sanción de cualquier servidor público, cuando tenga interés personal, familiar o de negocios en el caso, o pueda derivar alguna ventaja o beneficio para él o para las personas a las que se refiere la fracción XI.

$\mathrm{XV}$. Presentar con oportunidad y veracidad las declaraciones de situación patrimonial, en los términos establecidos por la Ley.

XVII. Supervisar que los servidores públicos sujetos a su dirección, cumplan con las disposiciones de este artículo.

Como puede apreciarse, el entramado administrativo de un poder como el Judicial debe hallarse ordenado a la consecución de un ambiente de imparcialidad que permita al juzgador hacer justicia sin que sus intereses entren en conflicto con los de alguno de los justiciables o con los del Estado mexicano. La presencia y la promoción (por lo demás, en sí misma prohibida, como indica la fracción XIV) de familiares en los diversos circuitos o en órganos jurisdiccionales distintos al propio, multiplica exponencialmente los riesgos de conflicto de interés y hace sospechar de inaplicaciones sistemáticas del principio de objetividad. 
Esta revista forma parte del acervo de la Biblioteca Jurídica Virtual del Instituto de Investigaciones Jurídicas de la UNAM

ESTUDIO SOBRE REDES FAMILIARES Y CLIENTELARES...

Continuemos con el ejercicio exegético:

Artículo 9o. El servidor público que deje de desempeñar su empleo, cargo o comisión deberá observar, hasta un año después de haber concluido sus funciones, lo siguiente:

a) En ningún caso aprovechará su influencia u obtendrá alguna ventaja derivada de la función que desempeñaba, para sí o para las personas a que se refiere la fracción XI del artículo anterior.

b) No usar en provecho propio o de terceros, la información o documentación a la que haya tenido acceso en su empleo, cargo o comisión y que no sea del dominio público, y

c) Los servidores públicos que se hayan desempeñado en cargos de Dirección en el Instituto Federal Electoral, sus consejeros, y los magistrados del Tribunal Electoral del Poder Judicial de la Federación, se abstendrán de participar en cualquier encargo público de la administración encabezada por quien haya ganado la elección que ellos organizaron o calificaron.

En materia de auditoría, la LFRASP (artículo 26) ofrece símiles interesantes, en cuanto a la operación del principio de imparcialidad, con la función jurisdiccional, y también con la independencia que deben guardar los servidores públicos del CJF respecto de las áreas jurisdiccionales por cuyo orden administrativo deben velar.

En el caso del Código De Ética de la Auditoría Superior de la Federación (ASF), puede observarse cómo los principios se hallan especialmente robustecidos en razón de la función que cumple la ASF. Lo propio debería poder predicarse de los servidores administrativos en el Consejo de la Judicatura Federal. La ASF es un ejemplo a seguir, pues el nepotismo simplemente no existe en ella:

Principio de independencia. Los profesionales al servicio de la ASF deben actuar con independencia de criterio, libres de prejuicios o intereses de cualquier índole, con el fin de preservar la imparcialidad y objetividad a las que la institución está obligada.

Para la revisión de la Cuenta Pública Federal y del Informe de Avance de Gestión Financiera, que forma parte de ese documento, la ASF debe proceder con la independencia de juicio a que está obligada por la naturaleza misma de sus funciones y por la autonomía técnica que le otorga la Constitución.

En consecuencia, los profesionales a su servicio deben realizar una evaluación equilibrada de todas las circunstancias relevantes y elaborar sus conclusiones sin dejarse influir por prejuicios o intereses políticos, étnicos, religiosos, gremiales, económicos o de otra naturaleza. 
Esta revista forma parte del acervo de la Biblioteca Jurídica Virtual del Instituto de Investigaciones Jurídicas de la UNAM

\section{FELIPE BORREGO ESTRADA}

Los auditores están éticamente obligados a no intervenir en ningún asunto en el cual tengan algún interés personal, o de cualquier otra índole, que constituya un impedimento para desempeñar sus funciones con la debida imparcialidad y objetividad.

La Ley General de Responsabilidades Administrativas (LGRA) se expidió en el marco de la reforma estructural para el combate a la corrupción. Entró en vigor el 6 de julio de 2017. Entre varios objetos posee el de "Establecer los principios y obligaciones que rigen la actuación de los servidores públicos" (artículo 2-I) y el de "Crear las bases para que todo ente público (concepto que incluye al Poder Judicial) establezca políticas eficaces de ética pública y responsabilidad en el servicio público" (artículo 2-VI. Las cursivas son nuestras).

Por conflicto de interés la LGRA entiende "la posible afectación del desempeño imparcial y objetivo de las funciones de los servidores públicos en razón de intereses personales, familiares o de negocios" (artículo $3-\mathrm{VI})$.

Vista la cuestión desde nuestra óptica, se exige de los poderes públicos el dictar políticas eficaces (vgr., el servicio civil de carrera) para evitar la "posible afectación del desempeño parcial y objetivo" de la función pública, incluyendo por supuesto a la labor jurisdiccional y a aquella que administrativamente auxilia a la judicial. El combate eficaz al nepotismo, la endogamia y el clientelismo no es, en suma, potestativo u opcional. No basta con que exista el servicio de carrera judicial, que ha sido un paso positivo pero incompleto. Debe perfeccionarse con un servicio civil para las áreas administrativas del CJF.

En el mismo sentido, los artículos 6o. y 7o. de la LGRA establecen lo siguiente (destacamos en cursivas los elementos clave):

Artículo 6o. Todos los entes públicos están obligados a crear y mantener condiciones estructurales y normativas que permitan el adecuado funcionamiento del Estado en su conjunto, y la actuación ética y responsable de cada servidor público.

Artículo 7o. Los Servidores Públicos observarán en el desempeño de su empleo, cargo o comisión, los principios de disciplina, legalidad, objetividad, profesionalismo, honradez, lealtad, imparcialidad, integridad, rendición de cuentas, eficacia y eficiencia que rigen el servicio público. Para la efectiva aplicación de dichos principios, los servidores públicos observarán las siguientes directrices (destacamos sólo las pertinentes a este análisis):

II. Conducirse con rectitud sin utilizar su empleo, cargo o comisión para obtener o pretender obtener algún beneficio, provecho o ventaja personal, 
Esta revista forma parte del acervo de la Biblioteca Jurídica Virtual del Instituto de Investigaciones Jurídicas de la UNAM

ESTUDIO SOBRE REDES FAMILIARES Y CLIENTELARES...

o a favor de terceros, ni buscar o aceptar compensaciones, prestaciones, dádivas, obsequios o regalos de cualquier persona u organización.

III. Satisfacer el interés superior de las necesidades colectivas por encima de intereses particulares, personales o ajenos al interés general y bienestar de la población.

IV. Dar a las personas en general el mismo trato, por lo que no concederán privilegios o preferencias a organizaciones o personas, ni permitirán que influencias, intereses o prejuicios indebidos afecten su compromiso para tomar decisiones o ejercer sus funciones de manera objetiva.

IX. Evitar y dar cuenta de los intereses que puedan entrar en conflicto con el desempeño responsable y objetivo de sus facultades y obligaciones...

Aún más, se exige que las personas morales cuenten con una política de integridad que, entre otros elementos, incluya políticas de recursos humanos tendientes a evitar la incorporación de personas que puedan generar un riesgo a la integridad de la corporación (artículo 25, fracción VI). Ninguna razón impide que esta exigencia se extienda a los entes públicos, por supuesto.

En este sentido, entre varias adecuaciones normativas que requiere el PJF, conviene recordar que su Código de Ética parte de la base de que "en virtud de las innovadoras transformaciones que vive cada día la sociedad mexicana, es natural que los juzgadores en su interrelación cotidiana se involucren en esta dinámica, como acontece en otros sectores, dando ocasión a la generación de ligas de interés que podrían afectar su libre conciencia". Siendo que "es un derecho de los justiciables que la administración de justicia sea impartida por jueces con autoridad moral que garanticen una justicia accesible, pronta, completa, imparcial y previsible, basada en la letra o la interpretación jurídica de la ley y, a falta de ésta, en los principios generales del derecho, sin que se privilegie cualquier otro interés" sería adecuado que el propio Código de Ética, en los capítulos relacionados con la "objetividad", la "excelencia" y la "prudencia" del juzgador, establezca la obligación de crear un entorno que posibilite eficazmente evitar colocarse en situaciones de conflicto de interés. Es un tema de ética personal pero, también, de políticas públicas adecuadas y eficazmente instrumentadas. Huelga decir que el Código obliga a todos los funcionarios del CJF, incluyendo por supuesto a los jueces y magistrados.

En el plano internacional, la Convención de las Naciones Unidas contra la Corrupción, a la par de otros tratados y convenciones de los que México es parte, establece la necesidad de adoptar sistemas des- 
Esta revista forma parte del acervo de la Biblioteca Jurídica Virtual del Instituto de Investigaciones Jurídicas de la UNAM

\section{FELIPE BORREGO ESTRADA}

tinados a promover la transparencia de entidades públicas y privadas, la denuncia, la integridad corporativa, la prevención de conflictos de intereses, el uso de buenas prácticas comerciales, así como a establecer medidas y sistemas para exigir a las personas servidoras públicas que presenten declaraciones a las autoridades competentes en relación a sus actividades externas y con empleos, inversiones, activos y regalos 0 beneficios importantes que puedan dar lugar a un conflicto de intereses respecto de sus atribuciones como funcionarios públicos, entre otras situaciones:

Artículo 9o. Contratación pública y gestión de la hacienda pública.

1. Cada Estado Parte, de conformidad con los principios fundamentales de su ordenamiento jurídico, adoptará las medidas necesarias para establecer sistemas apropiados de contratación pública, basados en la transparencia, la competencia y criterios objetivos de adopción de decisiones, que sean eficaces, entre otras cosas, para prevenir la corrupción. Esos sistemas, en cuya aplicación se podrán tener en cuenta valores mínimos apropiados, deberán abordar, entre otras cosas (se menciona sólo el inciso pertinente): 15

e) Cuando proceda, la adopción de medidas para reglamentar las cuestiones relativas al personal encargado de la contratación pública, en particular declaraciones de interés respecto de determinadas contrataciones públicas, procedimientos de preselección y requisitos de capacitación... ${ }^{16}$

Las Normas de conducta para la vida pública también conocidas como Informe Nolan establecen algunas recomendaciones sobre los siete principios que han de inspirar la actuación de políticos y servidores públicos:

- Desinterés.

- Integridad.

- Objetividad.

- Responsabilidad.

- Transparencia.

- Liderazgo.

- Honestidad.

15 Insistamos la contratación de personal no tiene por qué hallarse exenta de cumplir con estos extremos.

16 Esto es predicable, en general, de todo servidor público en el ámbito de la gestión administrativa 
Esta revista forma parte del acervo de la Biblioteca Jurídica Virtual del Instituto de Investigaciones Jurídicas de la UNAM

ESTUDIO SOBRE REDES FAMILIARES Y CLIENTELARES...

Sobre el último de los mencionados, el juez Nolan refirió la importancia de que aquellos que ocupan cargos públicos estén obligados a declarar todos los intereses privados relacionados con sus responsabilidades públicas y de tomar medidas para solucionar cualquier conflicto que surja de tal forma que protejan el interés público. ${ }^{17}$

\section{Métodos para prevenir un conflicto de interés}

Un conflicto de interés puede ser detectado, informado y desarticulado voluntariamente, antes de que, con ocasión de su existencia, se provoquen irregularidades, colusión o corrupción.

El principal recurso para prevenir los conflictos de interés consiste en generar una declaración de intereses, la cual consiste en el reconocimiento que hacen las personas servidoras públicas que tienen atribuciones originarias, delegadas o por representación declarando las relaciones pasadas, presentes o potenciales con personas físicas o morales, de carácter familiar, profesional, personal, laboral, o de negocios, incluyendo los socios, directivos, accionistas, administradores, comisarios y demás personal responsable de sus procesos de ventas, comercialización, relaciones públicas o similares, susceptibles de ser favorecidos, beneficiados, adjudicados con motivo del ejercicio de las atribuciones que les confieren los ordenamientos jurídicos y administrativos. También deberá declarar lo correspondiente al cónyuge, a la persona con quien vive en concubinato, en sociedad en convivencia o dependiente económico. Toda la información proporcionada se encuentra protegida por el régimen propio de datos personales.

Las declaraciones de intereses también deben presentarlas los particulares participantes en contrataciones y concesiones en procesos de compra.

Curiosamente, antes de la reforma conocida como "3 de 3", la Ley Federal de Responsabilidades Administrativas de los Servidores Públicos no mencionaba a la declaración de interés, refiriéndose sólo y de manera escueta al conflicto de interés en el artículo 80., fracciones $X$ y XIV, con lo que se fijaba una obligación de abstención con relación a un

17 Nevado-Batalla Moreno, Pedro T., "Cumplimiento de la legalidad en la nueva cultura de gestión pública: propuestas y realidades en la lucha de la corrupción" en Rodríguez García, Nicolás y Fabián Caparrós, Eduardo E. (comps.), La corrupción en un mundo globalizado: Análisis Interdisciplinar, Madrid, Ratio Legis, 2004, pp. 104-105. 
Esta revista forma parte del acervo de la Biblioteca Jurídica Virtual del Instituto de Investigaciones Jurídicas de la UNAM

\section{FELIPE BORREGO ESTRADA}

posible interés personal, familiar o de negocios; así como el deber de informar por escrito a su superior inmediato. ${ }^{18}$

Otra forma muy interesante y efectiva de prevenir el conflicto de interés, máxime tratándose de áreas de servicio público no primordialmente dedicadas a las adjudicaciones y a los recursos materiales, es el servicio civil o profesional de carrera, al cual nos referiremos in extenso más adelante.

\section{D. ¿Cómo manejar un conflicto de interés?}

Como principio general, los servidores públicos tienen la obligación de atender con diligencia la LFRASP para la atención de cualquier situación en la que exista la posibilidad presente o futura de que las personas servidoras públicas que intervienen en cualquier procedimiento o acto administrativo, sus superiores jerárquicos o aquellos de quienes reciben la delegación de facultades o comisión, obtengan un beneficio adicional de cualquier naturaleza para ellos o para las personas con las que tienen o han tenido relaciones personales, familiares, laborales 0 de negocios.

Entre las herramientas que existen para enfrentar los conflictos está la posibilidad de determinar la suspensión temporal o definitiva, así como la declaración de nulidad y reposición de los procedimientos y procesos en materia de adquisiciones, arrendamientos, prestación de servicios, obra pública y servicios relacionados con la misma, enajenación, adquisición, transferencia y baja de bienes muebles e inmuebles; concesiones, permisos, almacenes e inventarios, así como en todos aquellos previstos en el marco normativo, incluyendo todas las consecuencias administrativas o legales que de éstos resulten.

¡Cuánto más puede decirse de las estructuras jerárquicas en las que laboran cotidianamente parientes y personas relacionadas con los tomadores de decisiones! Caigamos en la cuenta, simplemente, de la amenazante precariedad de las decisiones que se toman en ámbitos inficionados por el nepotismo.

18 Romero Gudiño, Alejandro, Visión integral del Sistema Nacional de Combate a la Corrupción, México, Inacipe, 2015, p. 383. 
Esta revista forma parte del acervo de la Biblioteca Jurídica Virtual del Instituto de Investigaciones Jurídicas de la UNAM

ESTUDIO SOBRE REDES FAMILIARES Y CLIENTELARES...

\section{E. Conflicto de Interés ${ }^{19}$ bajo los parámetros de la OCDE 20}

Las experiencias en el mundo en materia de conflictos de interés han arrojado una definición puntual de lo que las entidades públicas han de entender por conflicto de interés, así como sus modalidades (reales o potenciales). La Organización para la Cooperación y el Desarrollo Económico (OCDE) define el conflicto de intereses como aquel que se da entre las obligaciones públicas y los intereses privados de un servidor público, de manera que éstos puedan influir impropiamente en su desempeño. Este punto ha sido medular para establecer una base común de entendimiento.

La OCDE otorga prioridad a la identificación de las situaciones de riesgo, a fin de prevenirlas y gestionarlas. Esto comprende mecanismos como la declaración de los sujetos en conflicto, quienes hacen del conocimiento dicha circunstancia para que los órganos de decisión establezcan las medidas más idóneas, que en la práctica internacional son variadas.

Finalmente, la OCDE impulsa una política de prevención, gestión y resolución de los conflictos de interés, proveniente de los órganos de decisión y permeados hacia el resto de las instituciones públicas. En este caso, se debe definir la estrategia que se ha de seguir para prevenir, gestionar e incluso sancionar los conflictos de interés.

Dichas estrategias de prevención, gestión y resolución de conflictos de interés comprenden variadas acciones que "de acuerdo con OCDE" han funcionado en otros países y se podrían emular. A manera de ejemplo tenemos:

Mecanismos de prevención basados en códigos de ética, códigos de conducta y cursos de capacitación que ayuden al servidor público a comprender qué es un conflicto de interés y por qué se debe prevenir.

Áreas especializadas en conflictos de interés que guíen de forma concreta al servidor público sobre cómo debe declarar un conflicto de interés y qué elementos debe precisar (similar a lo que ocurre con la declaración patrimonial).

19 Gutiérrez Salazar, Miguel Ángel Los conflictos de interés y la responsabilidad pública en México, en http://rendiciondecuentas.org.mx/los-conflictos-de-interes-y-la-responsa bilidad- publica-en-mexico/.

20 Los países miembros de la OCDE son: Alemania, Australia, Austria, Bélgica, Canadá, Chile, Corea, Dinamarca, Eslovenia, España, Estados Unidos de América, Estonia, Finlandia, Francia, Grecia, Hungría, Irlanda, Islandia, Israel, Italia, Japón, Luxemburgo, México, Noruega, Nueva Zelanda, Países Bajos, Polonia, Portugal, Reino Unido, República Checa, República Eslovaca, Suecia, Suiza y Turquía. 
Esta revista forma parte del acervo de la Biblioteca Jurídica Virtual del Instituto de Investigaciones Jurídicas de la UNAM

\section{FELIPE BORREGO ESTRADA}

La obligación de que se presente una declaración de conflicto de interés, al ingreso, al servicio público, bien en el momento en que éste ocurra o el servidor público estime que puede acontecer. Aquí también se deben definir las posturas que se adoptarán frente a dicho escenario, como puede ser la inhibición del servidor público de ciertas actividades, su suspensión, o en el caso más extremo, su destitución. Desde luego, debe buscarse cierto detalle y no incurrir en minimalismos como actualmente acontece en el caso del CJF.

En la práctica internacional se exige que cuando se manifieste un conflicto de interés, se haga de la manera más exhaustiva y detallada posible, para que la autoridad cuente con elementos suficientes y esté en posibilidad de indagar y decidir lo que mejor convenga a la institución. Esto puede significar modificar la esfera laboral del servidor público e incluso su denuncia ante las autoridades disciplinarias del orden administrativo o penal.

El actual formato de declaración de eventual conflicto de intereses en el CJF no resiste un análisis mínimo conforme a las mejores prácticas y estándares internacionales, ni cumple con los extremos de la llamada reforma "3 de 3" y con los objetivos de la regulación nacional en materia de combate a la corrupción. De hecho, el artículo 48 de la LGRA establece que el Comité Coordinador del Sistema Nacional Anticorrupción expedirá los formatos "bajo los cuales los Declarantes deberán presentar la declaración de intereses". Es de esperarse que estos formatos sean mucho más completos que el actual modelo del CJF, que no cabe calificar sino como minimalista y, en buena medida, carente de información relevante para detectar el riesgo de intereses en conflicto. 
Esta revista forma parte del acervo de la Biblioteca Jurídica Virtual del Instituto de Investigaciones Jurídicas de la UNAM http://www.juridicas.unam.mx/ https://biblio.juridicas.unam.mx/bjv https://revistas.juridicas.unam. $\mathrm{mx} /$

DOI: http://dx.doi.org/10.22201/iij.24487929e.2017.26.12316

ESTUDIO SOBRE REDES FAMILIARES Y CLIENTELARES...

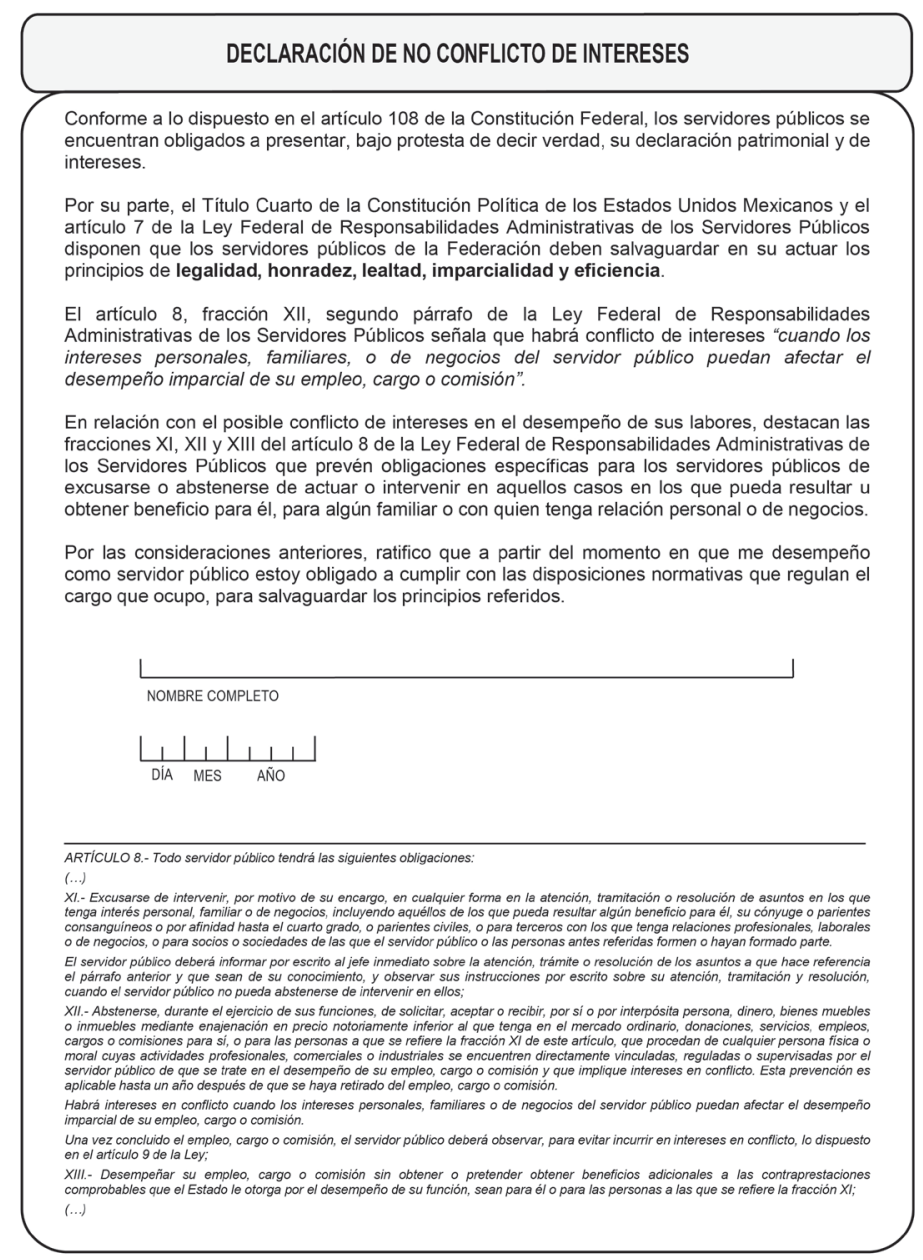

\section{EL SERVICIO CIVIL DE CARRERA}

\section{1. ¿En qué consiste?}

La declaración de potencial conflicto de intereses en un formato adecuado, con ser deseable, no es suficiente para cubrir los extremos de contratación administrativa que un Estado constitucional y democrático de derecho exige. 
Esta revista forma parte del acervo de la Biblioteca Jurídica Virtual del Instituto de Investigaciones Jurídicas de la UNAM

\section{FELIPE BORREGO ESTRADA}

Para ser imparcial, la función pública requiere de un sistema de nombramientos basado en el principio de objetividad. ${ }^{21}$ El servicio civil de carrera parte, ante todo, de la necesidad de nombrar al funcionariado a partir de tres consideraciones exclusivas: Mérito, capacidad y vocación de servicio. ${ }^{22} \mathrm{~A}$ cien años de que Venustiano Carranza lograra incluir en el texto de la Constitución los principios de estabilidad e inamovilidad judicial ${ }^{23}$ que Emilio Rabasa consideraba indispensables para el adecuado e imparcial desarrollo de la función jurisdiccional, las amenazas se presentan en forma diversa, como hemos sugerido en páginas anteriores, el riesgo está no sólo en las plazas jurisdiccionales, sino en las plazas administrativas al servicio del PJF (tanto al interior de los órganos como en el CJF central), y en la forma en la que se realizan los nombramientos y las adscripciones.

En efecto, el tercer párrafo del artículo 97 dispone que "los magistrados y jueces nombrarán y removerán a los respectivos funcionarios y empleados de los Tribunales de Circuito y de los Juzgados de Distrito, conforme a lo que establezca la ley respecto de la carrera judicial". Concebida como una regulación tendente a dotar de autonomía de gestión a los juzgadores, la disposición ha traído efectos colaterales indeseables, como es la multiplicación de redes clientelares ad intra de los órganos jurisdiccionales o bien con cruzamientos y "enroques" entre los diversos circuitos. ${ }^{24}$ Inclusive en los ámbitos más restrictivos de la administración, como es el judiciario, reconoce Lanz Cárdenas que "se hacen permutas

21 Lanz, Reflexiones..., p. 121. El nepotismo resulta "tanto más acentuado cuanto menores sean la libertad de expresión y las posibilidades de vigilancia ejercida por la oposición Otra circunstancia que facilita el nepotismo es la mala organización de la administración pública y de modo más concreto el mal sistema de ingreso a la misma". Gutiérrez Salazar, Miguel Ángel, op. cit., p. 129.

22 Haro Bélchez, Guillermo, Servicio público de carrera: tradición y perspectivas, México, INAP-Miguel Ángel Porrúa, 2000, p. 83.

23 Estos principios de ninguna manera deben entenderse, tal cual se ha hecho equivocadamente, como generadores de un derecho para el juzgador en el sentido de no poder sufrir movimientos o cambios de adscripción. El CJF debe reivindicar su facultad amplísima para realizar estos cambios por motivos de conveniencia en el servicio, como ocurre en las materias militar o diplomática.

24 Por "redes clientelares" entendemos lo que para el periodo 1917-1994 estudiaron Pozas Loyo, Andrea y Ríos Figueroa, Julio en Nacimiento y desarrollo de las redes clientelares en México, si bien el citado estudio se halla referido a los "pactos de caballeros" que permitieron a los ministros de la SCJN generar sus personales redes de influencia y designación de funcionarios. La creación del CJF quiso, en buena medida, abolir tal situación. Los "enroques" han sido estudiados, con el nombre de "nepotismo cruzado" por Tondopó Hernández, Carlos Hugo en La familia del Poder Judicial de la Federación, México, IIJ UNAM, 2010. 
Esta revista forma parte del acervo de la Biblioteca Jurídica Virtual del Instituto de Investigaciones Jurídicas de la UNAM

ESTUDIO SOBRE REDES FAMILIARES Y CLIENTELARES...

totalmente reprochables entre quienes tienen la facultad para autorizar nombramientos en la misma jurisdicción, ya que unos funcionarios confieren nombramientos a los familiares de otros y, así, operan de manera recíproca". ${ }^{25}$

Como puede apreciarse, el precepto constitucional relaja a la ley secundaria el respeto al escalafón en nombramientos, y limita tal respeto a la "carrera judicial". Ello, en la práctica, ha provocado discrecionalidad en los nombramientos administrativos que, encima, pueden implicar acceso a la carrera judicial sin necesidad de habilitación previa, dado que los "oficiales judiciales" no tienen que pasar prueba alguna para ser contratados.

No sólo magistrados de circuito y jueces de distrito logran generar redes clientelares haciendo mal uso de esta atribución. Los números muestras que muchos secretarios, actuarios, oficiales y administrativos poseen familiares en el mismo circuito o en otros. Claramente influyen en la designación, y lo hacen sin que sea posible incoarles ningún tipo de responsabilidad. La situación se complica cuando se considera que muchos de ellos, sobre todo los secretarios, influyen en forma muy directa sobre las decisiones de los juzgadores.

En 1917 se tomó la decisión de eliminar el Ministerio de Justicia para evitar que el Poder Ejecutivo influyera en la gestión autonómica de las cuestiones jurisdiccionales. Pareciera que la solución definitiva a las cuestiones aquí planteadas se halla, sin embargo, muy lejana. No hay, empero, razón alguna para que no sea el CJF quien designe a los encargados de las plazas administrativas al servicio de los órganos jurisdiccionales.

Es posible crear un Servicio Civil para la carrera administrativa y judicial dentro del PJF. Este Poder, que tantas y tan profundas reformas ha experimentado desde 1994, puede dar un gran ejemplo a todo el Estado mexicano a través de un cabal servicio de carrera que:

1. Evite potenciales conflictos de interés y minimice el riesgo de que se actualicen.

2. Consolide la autoridad y legitimidad de las decisiones jurisdiccionales, presumidas socialmente como tomadas con absoluta objetividad.

3. Transparente los procesos de ingreso y permanencia de los servidores públicos a través de criterios objetivos y reglas claras.

Las dos vertientes de Servicio Civil dentro del PJF (carrera judicial y servicio administrativo) implicarían en sentido óptimo la expedición de

25 Lanz, Reflexiones..., p. 144. 
Esta revista forma parte del acervo de la Biblioteca Jurídica Virtual del Instituto de Investigaciones Jurídicas de la UNAM

\section{FELIPE BORREGO ESTRADA}

sendas leyes (o, cuando menos, la reforma a la Ley Orgánica del PJF), sin perjuicio de que los principios que rigen las disposiciones generales sobre el servicio de carrera en México son perfectamente aplicables a los servidores del Departamento Judiciario. Se requiere, además, una reforma al artículo 97 constitucional a fin de evitar la discrecionalidad actualmente conferida a jueces y magistrados para el nombramiento del personal a su cargo. Una revisión de la cuestión sindical, incluyendo las condiciones generales de trabajo y la determinación de qué servidores públicos deben estar sindicalizados, es también imprescindible. Pensemos solamente, por vía de ejemplo, en el estatuto de los secretarios de juzgado y tribunal.

Al respetarse el principio de reserva de ley en esta materia, el diseño institucional alineará adecuadamente los incentivos para evitar intromisiones en las decisiones jurisdiccionales, al tiempo en que se endurecerá el régimen de responsabilidades para evitar prácticas abusivas, como son las nepóticas o clientelares.

Así las cosas, puede afirmarse que los servicios de carrera administrativa y jurisdiccional dentro del PJF son elementos fundamentales para la consolidación de la transición democrática en la República.

Ahora bien, no es necesario aguardar a la reforma constitucional y a la expedición de leyes para comenzar a evitar el conflicto de interés y las prácticas clientelares en el CJF. Es imprescindible colocar trabas inmediatas a la arbitrariedad. Para ello, se impone la reforma de algunos criterios que han impedido avanzar en un sentido objetivo y transparente. En términos más claros, mientras no se logren las reformas constitucionales y legales pertinentes, el CJF debe expedir y mantener políticas, criterios y acuerdos eficaces para abordar estos temas.

Es necesario atacar frontalmente las políticas institucionales que justifican el nepotismo y la endogamia, o que no los combaten decididamente. Analícese, el siguiente ejemplo, de suyo muy débil, incluso en cuanto a su naturaleza jurídica, pero escalable en lo relativo a sus alcances y eficacia:

Acuerdo General del Pleno del Consejo de la Judicatura Federal, que reglamenta la carrera judicial y las condiciones de los funcionarios judiciales.

Artículo 72. La circunstancia de que un Magistrado de Circuito o Juez de Distrito adquiera alguno de los parentescos por afinidad o civil, a que se refiere la fracción XI del artículo 8 de la Ley Federal de Responsabilidades Administrativas de los Servidores Públicos con alguno de los servidores públicos adscritos al mismo órgano jurisdiccional del que sea titular, no hace cesar el nombramiento respectivo, previamente expedido, ni impide que los funcionarios involucrados continúen en el disfrute de sus derechos 
Esta revista forma parte del acervo de la Biblioteca Jurídica Virtual del Instituto de Investigaciones Jurídicas de la UNAM http://www.juridicas.unam.mx/ https://biblio.juridicas.unam.mx/bjv https://revistas.juridicas.unam.mx/

ESTUDIO SOBRE REDES FAMILIARES Y CLIENTELARES...

laborales; con excepción del caso de que se trate del matrimonio celebrado por el titular con uno de esos servidores públicos.

En el caso de que en algún órgano jurisdiccional o área administrativa del Consejo se hubiese extendido un nombramiento de base, interino o de confianza a persona o personas que fuesen cónyuge o parientes consanguíneos o por afinidad hasta el cuarto grado de algún titular; éste no podrá a su vez, extender nombramientos de ningún tipo, respecto de personas que resultaren cónyuge o parientes consanguíneos o por afinidad hasta el cuarto grado del titular del órgano jurisdiccional o área administrativa del Consejo, donde se encuentren adscritos sus allegados.

Algunos criterios jurisdiccionales, incluso, fomentan el conflicto de interés y parten de una petición de principio en el sentido de que los juzgadores son, esencialmente y sin discusión, neutrales e imparciales:

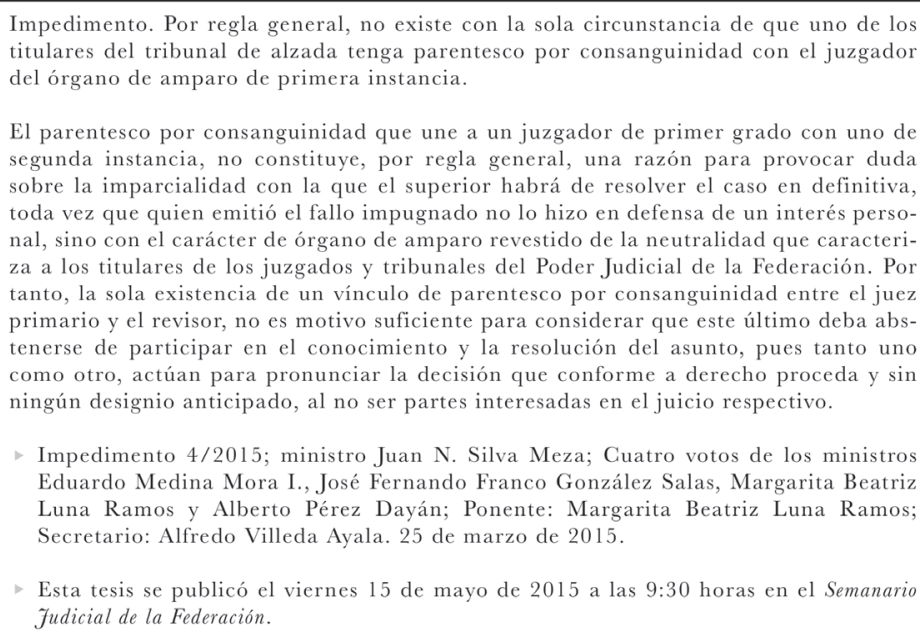

Impedimento 4/2015; ministro Juan N. Silva Meza; Cuatro votos de los ministros Eduardo Medina Mora I., José Fernando Franco González Salas, Margarita Beatriz Luna Ramos y Alberto Pérez Dayán; Ponente: Margarita Beatriz Luna Ramos; Secretario: Alfredo Villeda Ayala. 25 de marzo de 2015.

Esta tesis se publicó el viernes 15 de mayo de 2015 a las 9:30 horas en el Semanario Judicial de la Federación.

Así las cosas, puede decirse que no resultan pacíficos los criterios que hasta aquí hemos sostenido en materia de imparcialidad y objetividad judicial. Nos parece, sin embargo, que nuestro diagnóstico es preciso y que la problemática requiere instrumentar soluciones en el muy corto plazo.

\section{Experiencias comparadas}

Si bien es cierto que el servicio civil de carrera administrativa español excluye expresamente de su regulación (la única entre las analiza- 
Esta revista forma parte del acervo de la Biblioteca Jurídica Virtual del Instituto de Investigaciones Jurídicas de la UNAM

\section{FELIPE BORREGO ESTRADA}

das, por cierto, que goza de un nivel supremo, esto es, que está incluida en la Constitución de 1978) al funcionariado jurisdiccional, y que la formación del personal administrativo de los juzgados españoles no se confía al Instituto Nacional de Administración Pública, ${ }^{26}$ también lo es que el funcionariado judicial se encuentra sujeto a pruebas para su habilitación e ingreso al cauce de la carrera judicial y a exámenes de oposición para la dotación de las plazas, y que su formación se encuentra confiada a una Escuela Judicial de alto prestigio y renombre, dependiente del Consejo General del Poder Judicial, organismo que posee una Comisión "de Escuela Judicial". Nadie puede acceder, en consecuencia, al nivel más bajo del escalafón de la carrera judicial sin acreditar los exámenes que en última instancia son responsabilidad del Consejo a través de la Escuela.

En Francia, de igual forma, la Escuela Nacional de la Magistratura se hace cargo de los altos estudios para el funcionariado, con la peculiaridad de que se incluye a los servidores públicos del ámbito de la procuración de justicia. Nadie accede tampoco al ámbito del servicio judicial de carrera sin acreditar las pruebas de la Escuela, que es reputada como la casa de estudios de más alto nivel y rigor formativo en el país.

Mención especial merece Chile, pues a raíz de la instrumentación del sistema procesal penal de corte acusatorio y adversarial, la administración de los tribunales y de las salas de audiencia ha quedado a cargo de profesionales administrativos ajenos al conocimiento estrictamente jurídico. Estos administradores forman parte del servicio civil de carrera. Existen una Corporación Administrativa del Poder Judicial, dependiente de la Corte Suprema, y una Academia Judicial, encargada del perfeccionamiento de todos los miembros del Poder Judicial.

Estas experiencias resultan referentes ineludibles para, de conformidad con las circunstancias y peculiaridades mexicanas, plantear una recomposición de la organización y tareas a cargo del IJF.

\section{EL ACCESO A LA CARRERA JUDICIAL}

Por todo lo que se ha expuesto y probado, resulta inconcuso que debe establecerse un régimen estricto de formación y acceso desde la categoría más baja de la carrera (oficial judicial) para conseguir que sólo quienes hayan pasado las pruebas de habilitación puedan seguir el cauce de la carrera a través de sucesivos exámenes de oposición (sin perjuicio de

26 Haro, Servicio público, pp. 81-83. 
Esta revista forma parte del acervo de la Biblioteca Jurídica Virtual del Instituto de Investigaciones Jurídicas de la UNAM

ESTUDIO SOBRE REDES FAMILIARES Y CLIENTELARES...

que para las categorías de jueces y magistrados se puedan convocar concursos abiertos a juristas externos). ${ }^{27}$

\section{El actual "examen de aptitud" para las categorías inferiores}

Sólo los jueces y magistrados presentan actualmente exámenes de oposición. Para las categorías inferiores se requiere un "examen de aptitud" que aplica el IJF. Los oficiales judiciales, como ha quedado dicho, ingresan al cauce de la carrera judicial por designación simple de los titulares de órganos.

El "examen de aptitud" no es suficiente y, en muchos casos (como los de secretarios de juzgado) carece de pertinencia académica. El sistema de habilitación previa a la designación por oposición, en cambio, disminuye los incentivos perversos que favorecen nepotismo, favoritismo, abusos, y conformación de redes clientelares, y alinea los incentivos positivos para el rigor formativo y el desempeño profesional de las funciones jurisdiccionales.

\section{Propuesta: Examen de admisión a los estudios que ofrece} el Instituto de la Judicatura Federal. Habilitación para ser elegible. Incentivos positivos. Transparencia y objetividad

El ingreso a la carrera judicial, desde el nivel mínimo, debe darse a través de exámenes de habilitación. Quienes los acrediten deberán proceder a formarse en el IJF para poder presentar exámenes de oposición y ocupar las plazas.

Algo similar ocurrirá con los habilitados para ocupar plazas administrativas en el PJF. El IJF les brindará la formación que requieran para optar por plazas de gestión administrativa. Sin violentar la legislación laboral, por supuesto, y sin contravenir el régimen de condiciones de trabajo acordado con el sindicato, es perfectamente posible dotar de transparencia, rigor y objetividad el mecanismo que se propone.

Podríamos sistematizar las Soluciones a las problemáticas expuestas en la siguiente forma:

1. Reformar el tercer párrafo del artículo 97 de la Constitución general de la República para evitar la discrecionalidad en el nom-

27 Una interesante y completa propuesta de reforma legislativa, incluso en perspectiva comparada, puede hallarse en Alfaro Telpalo, Raúl y Coello Cetina, Rafael, El sistema para la designación de magistrados de circuito y jueces de distrito, México, Tirant lo Blanch, 2015. 
Esta revista forma parte del acervo de la Biblioteca Jurídica Virtual del Instituto de Investigaciones Jurídicas de la UNAM

\section{FELIPE BORREGO ESTRADA}

bramiento del personal de juzgados y tribunales pertenecientes al PJF.

2. Dotar de mayor independencia al CJF respecto de la SCJN en asuntos como la disciplina, el nombramiento y adscripción de juzgadores, etcétera, en los que el conocimiento y experiencia técnica del CJF se hallan acreditados en razón de su especialidad.

3. Bases que doten de certeza al desarrollo de la carrera judicial y que creen el servicio civil de carrera administrativa dentro del PJF.

4. Ajustes normativos, en tal sentido, a la Ley Orgánica del Poder Judicial de la Federación y a la legislación laboral, además de expedición de diversas leyes, con el objeto de armonizar las características específicas del servicio civil en el PJF y las bases laborales establecidas en los diversos cuerpos normativos.

5. Reforzamiento de los mecanismos de transparencia y rendición de cuentas, en materia de nombramientos y adscripciones.

6. Perfeccionamiento del servicio de carrera judicial e instauración del servicio de carrera de personal administrativo para:

- Evitar conflictos de interés.

- Consolidar la autoridad y legitimidad de las decisiones del PJF.

- Transparentar los procesos de ingreso y permanencia de los servidores públicos.

- Evitar adscripciones de parientes en un mismo circuito judicial, así como los "enroques" para burlar la reglamentación.

- Fomentar la rotación del personal.

- Establecer procesos imparciales y objetivos de designación y adscripción, a través de las figuras de Habilitación, Formación, Concurso de Oposición y Declaración pública de eventual conflicto de intereses.

Es también necesario, por otro lado:

- Recomponer la mística de servicio que debe caracterizar al juzgador, a través de la convicción en torno a valores y principios propios de la Justicia.

- Reconfigurar el actual Instituto de la Judicatura Federal para transformarlo en una Escuela de Saberes Judiciales generales, incluyendo los de gestión administrativa, bajo la regulación, vigilancia y coordinación del CJF.

- Practicar de inmediato un diagnóstico integral al CJF en cuanto a su estructura, organización y funcionamiento. 
Esta revista forma parte del acervo de la Biblioteca Jurídica Virtual del Instituto de Investigaciones Jurídicas de la UNAM

ESTUDIO SOBRE REDES FAMILIARES Y CLIENTELARES...

- Facilitar que el CJF ordene cambios de adscripción de los titulares de órganos jurisdiccionales, para prevenir los conflictos de interés.

Como hemos visto, uno de los mecanismos más efectivos al efecto de profesionalizar la función pública y minimizar la generación de conflictos de interés y redes clientelares se halla en la estructuración efectiva de un servicio profesional de carrera. Es imprescindible pensar en un proyecto de regulación que se haga cargo del interesante y poco explorado tema de los servidores públicos del Poder Judicial adscritos a servicios no jurisdiccionales, sino administrativos. Se propone, en consecuencia, la emisión de una Ley del Servicio Civil de Carrera para el Personal Administrativo del PJF, así como el perfeccionamiento en la regulación de la carrera judicial.

Para acreditar la existencia de redes clientelares y nepóticas, se han incluido como parte de este trabajo, en calidad de anexos, los datos obtenidos en la investigación empírica desarrollada en los circuitos. Las cifras y los porcentajes hablan por sí mismos de una situación incompatible con la dignidad de la función jurisdiccional y con la naturaleza del Consejo de la Judicatura Federal como uno de los pilares del Estado de derecho en México.

\section{Metodología EMPLEAdA}

Protocolo de recopilación de información

Objetivo: Recopilar información de los servidores públicos que cuenten con familiares en el Poder Judicial de la Federación a fin de generar un diagnóstico sobre las afectaciones que esto le puede ocasionar al justiciable.

\section{Método de recopilación}

Entrevistas: realizadas en los circuitos del 28 de enero del 2016 al 31 de enero del 2017.

Contexto:

1. Vaciar la información recopilada en el formato previamente establecido. 
Esta revista forma parte del acervo de la Biblioteca Jurídica Virtual del Instituto de Investigaciones Jurídicas de la UNAM

\section{FELIPE BORREGO ESTRADA}

2. Realizar la operación matemática que determine el porcentaje de servidores públicos con familiares.

Información periodística: reportajes realizados por distintos medios de comunicación en los cuales se describen las redes familiares de jueces y magistrados adscritos en un mismo circuito.

\section{Contexto (información proporcionada)}

1. $h t t p: / / w w w . e l u n i v e r s a l m a s . c o m . m x / c o l u m n a s / 2015 / 02 / 111351 . p h p$.

2. $h t t p: / / d i a r i o . m x / N a c i o n a l / 2014-05-22 \_f b a 7676 d / t r a b a j a n-e n-p o d e r-$ judicial-12-familiares- del-presidente-de-tribunal-electoral/.

3. $h$ ttp://www.jornada.unam.mx/2014/07/07/politica/011n1pol.

4. http://zonafranca.mx/el-nepotismo-es-normal-dentro-del-poder-judi cial-abogados/.

5. http://www.vanguardia.com.mx/juecesymagistradosreincidenenne potismo-2107673.html.

\section{Referencias}

1. Diccionario Biográfico del Consejo de la Judicatura Federal

Información pública obtenida a través de la página de Internet del Consejo de la Judicatura Federal.

Contexto (información proporcionada): http://www.cjf.gob.mx/Directorios. htm.

2. Información de litigantes y del propio personal de órganos jurisdiccionales

Información recopilada en las visitas realizadas del 28 de enero del 2016 al 31 de enero del 2017 en los circuitos.

\section{Contexto}

Determinado con base en información proporcionada por litigantes y el propio personal de los Circuitos.

\section{Validación}

Los datos fueron corroborados a través de los medios antes descritos. 
Esta revista forma parte del acervo de la Biblioteca Jurídica Virtual del Instituto de Investigaciones Jurídicas de la UNAM

Elaboración de tablas de información:

Para evitar que los datos de identificación personal, y laborales, sean utilizados para una finalidad distinta para la cual fueron proporcionados, para prevenir con ello se afecten otros derechos y libertades, se llevó a cabo una sustitución de datos con claves de identificación. 